\title{
Conceptualizing the Internet Compulsive-Buying Tendency: What We Know and Need to Know in the Context of the COVID-19 Pandemic
}

\author{
Hui-Ling Huang ${ }^{1}\left(\mathbb{D}\right.$, Yue-Yang Chen ${ }^{2, *} * \mathbb{C}$ and Shan-Ciao Sun ${ }^{2}$ \\ 1 Department of Business Administration, Chang Jung Christian University, Tainan City 71101, Taiwan; \\ ling@mail.cjcu.edu.tw \\ 2 Department of Business Administration, I-Shou University, Kaohsiung City 84001, Taiwan; \\ atheloveu@yahoo.com.tw \\ * Correspondence: ray@isu.edu.tw
}

check for updates

Citation: Huang, H.-L.; Chen, Y.-Y.; Sun, S.-C. Conceptualizing the Internet Compulsive-Buying Tendency: What We Know and Need to Know in the Context of the COVID-19 Pandemic. Sustainability 2022, 14, 1549. https://doi.org/ $10.3390 /$ su14031549

Academic Editors: Shang-Pao Yeh, Ren-Fang Chao, Tungju $\mathrm{Wu}$, Chi-Lu Peng and Weng-Marc Lim

Received: 16 December 2021

Accepted: 18 January 2022

Published: 28 January 2022

Publisher's Note: MDPI stays neutral with regard to jurisdictional claims in published maps and institutional affiliations.

Copyright: () 2022 by the authors. Licensee MDPI, Basel, Switzerland. This article is an open access article distributed under the terms and conditions of the Creative Commons Attribution (CC BY) license (https:// creativecommons.org/licenses/by/ $4.0 /)$.

\begin{abstract}
Over the past decade, new innovative products and services have been introduced into the marketplace using advanced technology. The enticement of new products lures consumers to buy compulsively. Because of the convenience and the characteristics of online shopping, it will increase the incidence of compulsive-buying behavior. Meanwhile, due to the fact that the COVID-19 pandemic is continuing to spread around the world, consumers may change their decision-making and behavior to shop online more frequently and intensively. The repetitive shopping online means more cardboard, delivery transportations, and vehicles and that more goods will be produced. It will result in an unfriendly result for the environment. Given the critical role of compulsive buying in the emerging Internet retail environment, it is necessary to develop and validate an instrument to measure the Internet compulsive-buying tendency (ICBT). Therefore, a rigorous measurementscale-development procedure was applied to evaluate the initial 31 items. After two rounds of data collection and assessment, the final instrument contained 18 items that fall into four subconstructs: the tendency to spend online, feelings about online shopping and spending, dysfunctional online spending, and online post-purchase guilt. These factors can provide a basis for predicting tendencies toward Internet compulsive shopping and can be used to evaluate consumers' abnormal behavior in online-shopping circumstances.
\end{abstract}

Keywords: Internet compulsive buying; Internet compulsive-buying tendency (ICBT); measurementscale development

\section{Introduction}

In addition to using the Internet as a virtual channel that is distinct from the traditional brick-and-mortar store to entice customers making transactions online [1], service providers host many amenities on the Internet for for-profit enterprises and institutions. Moreover, as a result of technological advance and the introduction of many innovative processes and services, the life cycle of a substantial number of commodities has been greatly shortened. Thus, even without a supply shortage, innovative items are continually being introduced into the market to attract consumers, which, combined with the power of advertising media, makes it difficult for individuals to satisfy their needs in the pursuit of material desires [2]. Recently, under the scourge of the COVID-19 pandemic, many consumers rely heavily on online shopping to avoid human-to-human connections in order to decrease the risk of spreading the virus. In the past, people went shopping from physical sites to enjoy themselves by interacting with others face to face. However, when traditional shopping becomes more difficult, or when it may even be scary, people are increasingly inclined to shop online. The fact that consumers were already embracing online retailers with open arms made transitions from cyberspace considerably easier and necessity. This change 
in individual behavior also leads to a dramatic increasing number of consumers to shop online continually and sustainably.

Meanwhile, in the modern world, individuals are under a substantial amount of pressure. Therefore, they tried to find ways to reduce pressure and temporarily relieve mental and physical stress by external stimulation. In this vein, the advantages such as ease of use, convenience, and attractive product displays that online shopping offers precisely strengthen consumer's Internet buying behavior [3]. Since many buyers escape the supervision of family and friends, with the increasing sales of online shopping and the changing values of the public, the investigation of the negative impact of online shopping on impulsive [4,5], compulsive [6,7], and addictive [8] buyers and the related factors is increasingly important to academicians and practitioners [6]. Moreover, because of the mass media and the promotion of individual online shopping, the group of consumers that suffers from Internet compulsive-buying behavior, for example, dysfunctional and excessively spending and wasting resources $[9,10]$, is increasing $[11,12]$. It may become a new, worthwhile focus of research attention $[13,14]$.

In fact, empirical studies of compulsive buying have evaluated the related topics in physical channels (e.g., [11,15-18]); however, not only has little attention been devoted to discussion but also clear assessments of the compulsive-buying tendency in the context of the Internet buying environment have not been provided. These limitations have created difficulties in replicating and validating findings in online-buying settings, especially for the measurement scale of the Internet compulsive-buying tendency (ICBT). It results in a research gap on this issue. Because the characteristics of the online buying environment is quite different from in-store shopping, online marketers and sociologists need a more concise and applicable instrument that measures ICBT in order to explain abnormal, negative consumer tendencies and that clearly identifies the personal traits of Internet compulsive buyers. Thus, the main objective of this current study was to focus on defining and developing the concept of ICBT and then validating a reliable instrument empirically to capture its underlying dimensions. The article is organized as follows. First, the concept of Internet compulsive buying and how it relates to the measurement is discussed. Next, the research methodology that was employed to develop ICBT measurement items is proposed, followed by the two rounds of data collection and the cutoff-point judgement for Internet compulsive buyers. Finally, key findings and implications are also highlighted.

\section{Literature Review}

\subsection{Compulsive Buying}

Since the early 1900s, the concept of compulsive buying has been proposed by Kraepelin [19] and Bleuler [20]. They named compulsive buying as a phenomenon of buying mania or oniomania, and it can be a pathological and reactive impulse, which includes excessive buying and dysfunctional buying behavior [21]. Then, $\mathrm{O}^{\prime}$ Guinn and Faber [17] indicated that compulsive buying is a constant and repetitive morbid behavior that arises from an individual requirement in order to reduce his/her stress or anxiety. Compulsive buying includes excessive buying and dysfunctional buying behavior and may lead to negative events and feelings [22]. It is believed that compulsive buying coexists with other psychiatric disorders, such as anxiety disorders, substance abuse, eating disorders, obsessive-compulsive disorder, and impulse-control disorders, particularly pathological gambling $[6,13,23]$. According to $\mathrm{O}^{\prime}$ Guinn and Faber [17], compulsive buying behavior is habitual, dysfunctional, repetitive purchasing and is the main response mechanism to negative events and negative emotions. Compulsive buyers purchase something to decrease anxiety and are not particularly interested in the item and do not hold high expectations regarding it. The consumer does not spend much time to find the items he or she wants to buy, and the goal of the purchase is to enjoy instant gratification [18]. Thus, they can reduce their anxiety and stress and strengthen a sense of self-realization through the continuous, repetitive purchasing of items that they do not need, which will ultimately harm the compulsive buyers or others [12]. 
From a financial perspective, the dysfunctional spending behavior without regard for financial conditions may result in problems, such as credit-card loans and family difficulties. From a psychological perspective, with each successive purchase, the resulting satisfaction becomes increasingly brief. Thus, depressive symptoms, such as anxiety and stress, become increasingly severe. Additionally, the persuasion of family and friends is often ineffective, which, coupled with disputes, results in more-serious psychological disorders or dysfunctional behavior [24].

\subsection{Internet Compulsive Buying}

Because of the convenience and ease of application, there are a number of consumers who prefer online shopping as consumers can go shopping at anyplace and can also enjoy timely shopping activities $[25,26]$. In addition, consumers can browse millions of products without appearing in the physical stores, and they can enjoy the same pleasure of shopping. Accordingly, the fast-growing e-commerce cyberspace provides businesses and consumers an efficient shopping channel that differs from traditional channels. In such a context, consumers are not interested in the technology per se but in how the Internet can enhance their shopping experiences and help them make better purchasing decisions [27]. With the popularity of online shopping, compulsive and addictive buyers may become potential consumers in the Internet environment $[7,8,12]$.

From the "Dark side" perspective of online shopping, the Internet also has its risks for consumers (e.g., dysfunctional consumer behavior). When consumers go shopping online, excessive consumer behavior may develop into Internet compulsive buying [11,12] Compulsive buyers tend to use the Internet or a television home-shopping channel alone at night in order to prevent others from discovering their dysfunctional purchase behavior and to avoid subjecting themselves to the views of others; therefore, in such a free and unfettered pace, consumers who shopped to improve their feelings or reduced psychological pressure previously are prone to more Internet compulsive buying intentions and behaviors [28,29]. The diversity of the items available on the Internet and the speed with which one can expect to receive purchased items have resulted in an increasing number of consumers relying on online shopping; such shopping may then evolve into addiction. LaRose and Eastin [12] mentioned that, due to the influence of mass communications and the change of types of shopping activities, different types of abnormal consumption behavior have emerged from the electronic-commerce environment. Greenfield [14] also indicated that because compulsive buyers seek a private opportunity for shopping without the influence of others, the percentage of compulsive buyers is higher in the online-shopping environment than in traditional (offline) stores.

As mentioned above, the concealment characteristic of the Internet supports the compulsive buyer's avoidance of contact with others and provides instant gratification; however, as it is characteristic of a compulsive buyer, soon after purchase, they may experience feelings such as loss and anxiety. In the long run, the dependence on online shopping may become aggravated and result in a substantial number of problems. Finally, individuals must be treated with medication in order to conquer the financial and personal problems caused by excessive purchases.

\section{Research Methodology}

\subsection{The Research Model}

Through the lens of related studies, the construct of the Internet compulsive-buying tendency (ICBT) that includes four key dimensions was proposed. These dimensions are the tendency to spend online, feelings regarding online shopping and spending, dysfunctional online spending, and online post-purchase guilt. It was anticipated that these four elements could be used to clearly measure the ICBT. The original research model is shown as Figure 1. 


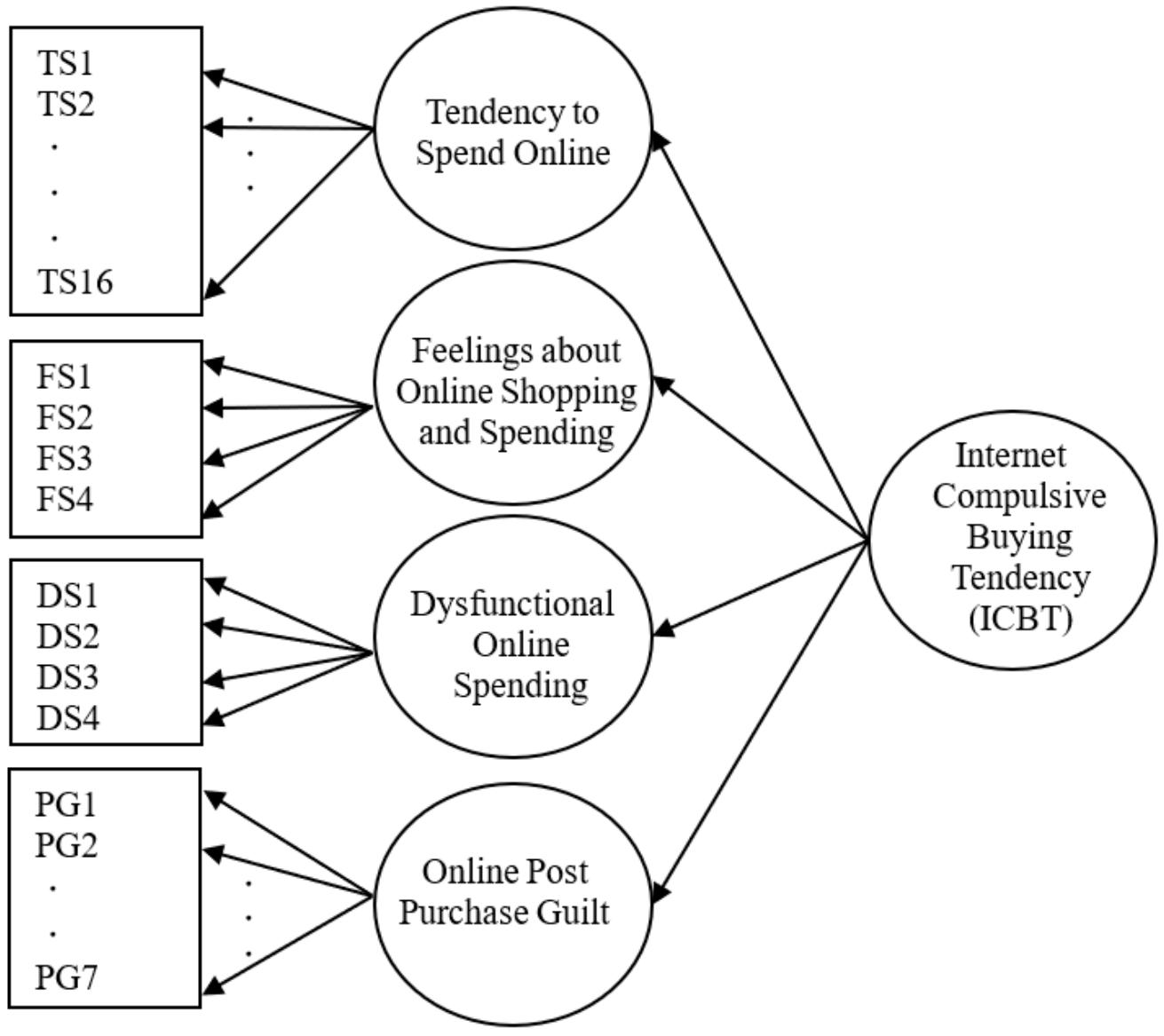

Figure 1. Research model.

\subsection{Operational Definition and the Measurement Items}

We defined the Internet compulsive-buying tendency as "the degree to which an individual is likely to make a chronic, repetitive Internet shopping behavior that arises from the needs to reduce his or her anxiety or stress and will result in negative events and feelings." Compared to the normal consumer, compulsive buyers have low self-esteem and often fantasize, desire interpersonal relationships, are prone to depression, and have high anxiety and a higher sense of identity. They purchase not for specific products $[16,17]$ but for lack of behavioral control [30]. Compulsive buying often results in a negative emotional state that will temporarily be improved through the process of buying; however, compulsive buyers feel guilt, shame, and depression and will hide or return the purchased item $[9,31]$. Consequently, compulsive buyers are subject to considerable torment from negative emotions; therefore, a measurement scale must incorporate the characteristics of obsessive-compulsive (e.g., "I often buy items that I do not need") and impulse-control disorders (e.g., "I am often impulsive in my buying behavior") [30].

Valence et al.'s [32] scale focuses on measuring the degree of compulsive-buying behavior. The authors indicated that this three-dimension scale (including the tendency to spend, reaction, and post-purchase guilt) could measure the tendency to spend for consumers. In contrast, Faber and O'Guinn [7] proposed a single construct with seven items to measure compulsive-buying behavior. They assumed that this single construct could be used to discern extreme compulsive buyers. However, Edwards [33] indicated that owing to its complex properties, compulsive buying is not a single dimension to reflect its psychometric characteristics. Thus, Edwards developed measurement indicators that consisted of the spending tendency, the spending motive, feelings regarding shopping and spending, dysfunctional spending, and post-purchase guilt. To sum up, following Faber and O'Guinn [7], Valence et al. [32], and Edwards [33], the construct of ICBT with four di- 
mensions was proposed. We aimed to develop a proper scale to evaluate the characteristics and attributes of Internet compulsive buyers that would allow for an understanding of this group. The operational definitions of each dimension are summarized in Table 1.

Table 1. Operational definition of construct.

\begin{tabular}{ll}
\hline \multicolumn{1}{c}{ Construct } & \multicolumn{1}{c}{ Operational Definition } \\
\hline Tendency to spend online & Consumer-related Internet-shopping tendency \\
\hline Feelings about online shopping and spending & $\begin{array}{l}\text { Consumer feelings regarding Internet } \\
\text { shopping and spending }\end{array}$ \\
\hline Dysfunctional online spending & $\begin{array}{l}\text { Degree of dysfunctional online spending from } \\
\text { the Internet derived from consumer's } \\
\text { consumption behavior }\end{array}$ \\
\hline Online post-purchase guilt & $\begin{array}{l}\text { Degree of feeling remorse and shame after the } \\
\text { Internet shopping passion of consumer fades }\end{array}$ \\
\hline
\end{tabular}

In this study, a multiple-item with 7-point Likert scale was used, which is anchored from " 1 = strongly disagree" to " 7 = strongly agree." The measurement items for each dimension are listed in the Appendix A along with their reference(s).

\subsection{Development Procedure for the Scale}

This study builds on the works of Churchill [34] and Hinkin [35] to construct and develop the scale for ICBT in a seven-step process for scale development and analysis. The procedure has been widely accepted and adopted in academic research. Moreover, the procedure provides explicit guidelines for its application and thus helped to improve the quality of the scale used in this study. The procedure for the scale development in this study is described as following:

Step 1: Specify the meaning and the constructs of the Internet compulsive-buying tendency. After a literature review, this present study defined four constructs, namely, the tendency to spend, feelings regarding shopping and spending, dysfunctional online spending, and online post-purchase guilt.

Step 2: Develop the items of ICBT. Based on the literature review and discussions with experts and researchers, the measuring items collected for each construct were compiled to obtain the items of the preliminary scale used in this study.

Step 3: The initial data collection. For the first round, questionnaires were distributed to online shoppers.

Step 4: Refinement of the scale for ICBT. The questionnaire for the preliminary scale was subjected to reliability testing and exploratory-factor analysis (EFA), and the items were refined based on the results.

Step 5: The second-round data collection. For the second round, questionnaires were also distributed to online shoppers.

Step 6: Reliability testing of the scale. The reliability of the scale was tested again using composite reliability.

Step 7: Validity testing of the scale. The validity of the scale was tested using discriminant validity, convergent validity, and nomological validity.

Step 8: Competing model comparison to demonstrate that the second-order hierarchy model is the superior one.

\subsection{Sampling and Classification of Internet Compulsive Buyers}

The unit of analysis were consumers who had experiences in online shopping. Convenience sampling and snowball data collection were used to distribute the questionnaires. An online survey questionnaire website (www.my3q.com, accessed on 12 May 2020) was chosen to design and create the questionnaire. An invitation with the link to the survey was distributed through e-mail, social-network websites, and several online-buying forums 
to friends and colleagues. Participants were asked to forward on to others in a snowball manner after completing the survey. For increasing the return rate of valid answers, we patronized for a compensation of NTD 100 for each respondent.

In order to determine which online consumers had a high tendency toward compulsive buying, the screening method developed by Faber and $\mathrm{O}^{\prime}$ Guinn [7] was used (the items are listed in the Appendix A; each was measured on a 5-point Likert-type scale). A score of -1.34 or smaller is considered as a compulsive-buying consumer. Studies have shown that consumers with compulsive buying spend more time on shopping websites and visit these sites more frequently [36,37]. Thus, individuals with compulsive-buying behavior also have the characteristics of Internet compulsive buying [30].

\section{Data Analysis and Results}

Since Steps 1 and 2 have already been described and discussed in previous sections, we then present the other six measurement-scale-development steps in the following sections.

\subsection{The Initial Data Collection (First-Round Data Collection)}

In total, 523 questionnaires were collected during the first round. Incomplete questionnaires and those questionnaires returned by users without Internet shopping experience were excluded. Finally, a total of 481 valid questionnaires were collected. Among them, 117 questionnaires indicated compulsive-buying behavior according to the criterion proposed in Faber and O'Guinn [7]. Therefore, in this study, the response rate of valid questionnaires from users who qualified as research subjects was $22.37 \%$. The data were compiled for the first-round study of the scale. Among the respondents, the percentage of females $(87.18 \%)$ was slightly higher than males $(12.82 \%)$; the majority of this group was aged 19 to 22 years $(40.17 \%)$, while $51.28 \%$ were students, and they were employed in the service industry $(28.21 \%)$. Additionally, the majority of this group had a bachelor's degree $(65.81 \%)$, followed by a high-school diploma $(11.97 \%)$, and six or more years of experiences in online shopping $(16.24 \%)$. The average weekly frequency of online shopping was 3.16 times, whereas the average monthly spending in online shopping was NTD 5842.

\subsection{Refinement of the Scale for ICBT}

\subsubsection{Item-to-Total Correlation}

This correlation represented a construct-to-factor reliability measure of the scale. Kerlinger and Lee [38] proposed the item-to-total correlation as a tool to measure construct validity. After the completion of the first item-to-total correlation for all the constructs, the results indicated that TS1, TS6, FS4, and DS1 were smaller than the threshold of 0.5 [39]. Therefore, these items were excluded from the item pool and subsequent analyses. Then, the second item-to-total correlation test was conducted again, and the results indicated that the item-to-total correlation values of all items were between 0.51 and 0.86 .

\subsubsection{Reliability Analysis}

Internal consistency refers to the relationship between the items of the scale. The more the items were related to one another, the higher the level of internal consistency was. Cronbach's $\alpha$ was used to test the reliability of the pre-test scale. If good reliability was obtained with multiple tests of the same target, the scale had consistency and stability. Nunnally [39] indicated that it is acceptable if the value of Cronbach's $\alpha$ is greater than 0.7.

For the first-round analysis, the results indicated that the internal-consistency coefficient of $\alpha$ of the scale was 0.91 for the "tendency to spend", 0.91 for "feelings regarding shopping and spending", 0.71 for "dysfunctional online spending", and 0.80 for "online post-purchase guilt", showing that all the reliabilities were greater than 0.7. In sum, after the item-to-total correlation and the Cronbach's $\alpha$ coefficient test, we found that the reliability of the scale used in this study was acceptable. Thus, all the items of the scale had good reliability. 


\subsubsection{Factor Analysis}

Factor analysis can reduce the redundancy of constructs to present its validity. First, the Kaiser-Meyer-Olkin (KMO) measure of sampling adequacy and Bartlett's test of sphericity were applied to determine whether a variable was suitable for factor analysis. The criteria of the KMO measure should be higher than the acceptable value of 0.5 [40]. Furthermore, Bartlett's test of sphericity could be used to measure the high correlation between variables; the significant-sphericity-test results indicated suitability for factor analysis. In this study, the $\mathrm{KMO}$ values of various constructs were from 0.67 to 0.90, and the results of Bartlett's test of sphericity were significant, which suggests that this study was suitable for factor analysis.

Because the primary purpose of this research was to develop a scale for measuring ICBT, EFA was conducted to verify the initial validity of the measurement items. The results were good when the factor loading value of all the factors was greater than 0.5 [41]. Consequently, the results showed that the factor loadings for each construct ranged from 0.68 to 0.94 , demonstrating a good validity of the constructs.

\subsection{The Second-Round Data Collection and Analysis}

How many samples should be collected in SEM is a critical issue. Although there is no generalized guideline for estimating sample size for SEM, a reasonable sample size for a CFA model ranges between 100 and 200 [41]. A rule of thumb is at least 5 or 10 times the number of parameters [42,43]. Following this premise, totally, there were 27 variables (parameters) to be estimated in our second-round research model. Thus, at least 155 samples were the minimum requirement for parameter estimations. In the secondround data collection and analysis stage, a total of 1070 questionnaires were collected. Thus, the sample size we used showed its representativeness in SEM analysis.

The data from the compulsive0buying samples indicated that there were more females (74.39\%) than males $(25.61 \%)$ within this group. Around forty percent of these samples aged from 19 to $22(40.19 \%)$. In addition, the majority of the sample was students $(56.45 \%)$ followed by those employed in the services industry (25.33\%). Moreover, $68.22 \%$ of the respondents held a bachelor's degree, followed by $12.62 \%$ who held a master's degree. The average online shopping expenditure reported in the month prior to completing the questionnaire was NTD4147.87.

To test the presence of non-response bias in our empirical data, we compared the early and late respondents in terms of key attributes: gender, age, job, and education. No significant differences were found by using $\chi^{2}$ test in the cross-tabulation between the variables. Thus, it means that the profile of the respondents did not show differences in their background with the results of the data analysis from the variables.

\subsection{Measurement Model and Analysis of Reliability and Validity}

For testing the basic assumptions of structural equation modeling (SEM), we conducted a P-P scatter plot to assess the assumption of normality. The plot showed that the quantile pairs fell nearly on a 45-degree straight line. It is, therefore, reasonable to conclude that the data were fit with the assumption of a normal distribution.

Bagozzi and Yi [44] and Fornell and Lacker [45] indicated that a perfect measurement model must be assessed by the following criteria: (1) reliability for the composite of measurements of a latent variable should exceed 0.6 and (2) the average variance extracted (AVE) from a set of measurements of a latent variable should exceed 0.5. Additionally, the AVE value can also be used to judge convergent validity [41,45]. By doing so, CFA must first be employed first to confirm the explained power for each indicator with its respective latent variable. Table 2 represents the values for each variable. 
Table 2. Scale properties for the measurement model.

\begin{tabular}{|c|c|c|c|c|c|c|}
\hline Construct & Item & Mean & SD & $\begin{array}{l}\text { Standardized } \\
\text { Loading }^{\text {a }}\end{array}$ & $C R^{b}$ & $\operatorname{AVE}^{c}$ \\
\hline \multirow{9}{*}{$\begin{array}{l}\text { Tendency to spend } \\
\text { online }\end{array}$} & & & & 0.96 & \multirow[t]{9}{*}{0.90} & \multirow[t]{9}{*}{0.54} \\
\hline & TS2 & 5.64 & 0.95 & 0.76 & & \\
\hline & TS3 & 5.50 & 0.99 & 0.69 & & \\
\hline & TS4 & 5.83 & 1.00 & 0.77 & & \\
\hline & TS5 & 5.44 & 1.19 & 0.83 & & \\
\hline & TS7 & 4.67 & 1.10 & 0.65 & & \\
\hline & TS9 & 5.35 & 1.09 & 0.77 & & \\
\hline & TS10 & 4.96 & 1.17 & 0.74 & & \\
\hline & TS11 & 4.83 & 1.37 & 0.66 & & \\
\hline \multirow{4}{*}{$\begin{array}{l}\text { Feelings about online } \\
\text { shopping and } \\
\text { spending }\end{array}$} & & & & 0.77 & \multirow[t]{4}{*}{0.92} & \multirow[t]{4}{*}{0.79} \\
\hline & FS1 & 5.45 & 1.08 & 0.84 & & \\
\hline & FS2 & 5.66 & 0.99 & 0.94 & & \\
\hline & FS3 & 5.77 & 0.92 & 0.88 & & \\
\hline \multirow{4}{*}{$\begin{array}{l}\text { Dysfunctional online } \\
\text { spending }\end{array}$} & & & & 0.85 & \multirow[t]{4}{*}{0.73} & \multirow[t]{4}{*}{0.53} \\
\hline & DS2 & 5.23 & 0.90 & 0.60 & & \\
\hline & DS3 & 4.98 & 0.84 & 0.66 & & \\
\hline & DS4 & 5.10 & 1.05 & 0.88 & & \\
\hline \multirow{5}{*}{$\begin{array}{l}\text { Online post-purchase } \\
\text { guilt }\end{array}$} & & & & 0.72 & \multirow[t]{5}{*}{0.82} & \multirow[t]{5}{*}{0.54} \\
\hline & PG1 & 4.43 & 1.24 & 0.51 & & \\
\hline & PG3 & 4.07 & 1.37 & 0.51 & & \\
\hline & PG4 & 4.79 & 1.28 & 0.92 & & \\
\hline & PG5 & 5.03 & 1.26 & 0.90 & & \\
\hline
\end{tabular}

Note: ${ }^{a}$ All item loadings are significant at $p<0.05^{\mathrm{b}}$ Composite reliability $(\mathrm{CR})=\left(\Sigma \mathrm{L}_{\mathrm{i}}\right)^{2} /\left(\left(\Sigma \mathrm{L}_{\mathrm{i}}\right)^{2}+\Sigma \operatorname{Var}\left(\mathrm{E}_{\mathrm{i}}\right)\right)$ ${ }^{c}$ Average variance extracted $(\mathrm{AVE})=\Sigma \mathrm{L}_{\mathrm{i}}^{2} /\left(\Sigma \mathrm{L}_{\mathrm{i}}^{2}+\Sigma \operatorname{Var}\left(\mathrm{E}_{\mathrm{i}}\right)\right)$.

An important step in scale validation is to assess the strength of measurement between the items and associated constructs. In the estimated model, items that demonstrate cross load, poor loading, and poor reliability were dropped, and the model was re-estimated in order to ensure that the data are a good fit with the measurement. We used the value of 0.5 as the threshold for factor-loading assessment [41]. The items of TS8, TS12-16, PG2, PG6, and PG7 were excluded from the subsequent analyses due to their poor loadings. After the items were excluded, CFA was retested. Finally, the results indicated that factor loading of all the items was greater than 0.5. In addition, the fit indices indicated that the dimensions were a good fit for the observed covariance among the item measures [44,46] $\left(\chi^{2}=389.28\right.$, d.f. $=122 ; \chi^{2} /$ d.f. $=3.19, p<0.001 ; \mathrm{AGFI}=0.80 ; \mathrm{CFI}=0.96 ; \mathrm{NFI}=0.95$; NNFI $=0.95$; SRMSR $=0.058$ ).

Composite reliability aims to measure the consistency between all of the indicators of one latent construct. The higher the composite reliability, the higher the level of internal consistency between the indicator and the more powerful the measurement of construct validity of potential variables. Bagozzi and Yi [44] suggested that composite reliability should be greater than 0.6. In this study, as shown in Table 2, the composite reliability of the various constructs ranged from 0.79 to 0.92 , which is in line with the recommended threshold value, suggesting that the latent variables of this study had internal consistency.

Finally, discriminant validity was assessed by the variance extracted test proposed by Fornell and Larcker [45]. AVE can be used to calculate the explanatory power of the average variance of various observed variables of one latent variable, and the results could be used to determine the validity of potential variables. The validity can be divided into convergent validity and discriminant validity, whereby the higher the AVE of convergent validity to the latent variable, the higher the convergent validity. The threshold of the AVE value must be greater than 0.5 [45]. As we can see in Table 2, after deleting the poor loading items, all the AVEs were greater than 0.5. Thus, the convergent validity was confirmed. Furthermore, discriminant validity was compared and determined using AVE and the 
squared values of the correlation coefficients of pairwise variables. The criterion was that the AVE value should be greater than the squared values of the correlation coefficients [45]. As shown in Table 3, the diagonal was the AVE value, and the non-diagonal was the square correlation coefficients, showing that the criterion was met, suggesting good discriminant validity of the scale.

Table 3. AVE and the correlation matrix.

\begin{tabular}{lcccc}
\hline \multicolumn{1}{c}{ Construct } & $\mathbf{1}$ & $\mathbf{2}$ & $\mathbf{3}$ & $\mathbf{4}$ \\
\hline 1. Tendency to spend online & 0.54 & & & \\
2. Feelings about online shopping and spending & 0.41 & 0.79 & & \\
3. Dysfunctional online spending & 0.39 & 0.19 & 0.53 & \\
4. Online post-purchase guilt & 0.28 & 0.34 & 0.36 & 0.54 \\
\hline
\end{tabular}

Note: The diagonal is the AVE value, and the non-diagonal is the square correlation coefficient. Correlations greater than 0.19 are significant at $p<0.05$.

\subsection{Assessment of Nomological Validity}

Nomological validity refers to "the degree to which predictions in a formal theoretical network containing a construct of interest are confirmed" [47] (p. 327). It is used to confirm the usefulness of a scale instead of testing a proposed hypothesis [48]. For assessment of the nomological validity of the scale, a nomological network can be developed to hypothesize the relationship between ICBT and the theoretical related variables from existing theory [49]. According to the Theory of Planned Behavior (TPB) [50], an individual's behavior has the ability to control self-volition. In other words, an individual has the ability to fully decide whether to act on the basis of free will. The most direct determinant of an individual's behavior is the behavioral intention, and other factors that may influence behavior are indirectly influenced by the behavioral intention. Therefore, the more positive an individual's intention toward behavior, the higher the possibilities of the behavioral intention. According to the research context of this study, it is reasonable to conclude that the higher the propensity of online compulsions to purchase, the more compulsive purchases a consumer will make. Previous studies also posited a direct relationship between online online-buying compulsive intentions and behavior [11,30,51] Thus, we conducted the correlation analysis between the summed scale scores for ICBT and Internet compulsive-buying behavior (the measurement scale with six items was derived from [7] and modified into the Internet-buying context). The findings showed that the ICBT construct had a significantly positive effect on the compulsive-buying-behavior construct $(\mathrm{r}=0.29, p<0.001)$. Therefore, the nomological validity of the proposed ICBT was confirmed.

\subsection{Competing Model Comparison}

In order to verify that the second-order covariation (hierarchy) model is the superior one, we proposed to compare the overall fit indices of different competition models with reference to the method proposed by Noar [52]. This series of models includes: the null model, the one-factor model, the first-order-and-uncorrelated-factors model, the first-orderwith-correlated factors model, and the second-order hierarchy model. The findings for each model were tested and are shown in Table 4 . As can be seen, the fit indices of each model improved significantly when compared with the null model. The $\chi^{2} /$ d.f., NNFI, CFI, RMR, and SRMR of the one-factor model and the first-order-with-unrelated-factors model did not reach the acceptable standard. In addition, while the $\chi^{2} /$ d.f. of the first-order-withcorrelated-factors model was close to the threshold value of 5, its NNFI, CFI, RMR, and SRMR were not better than those of the second-order hierarchy model. Therefore, we can conclude that the second-order (CFA covariance) model was retained as the model of best fit, and it was shown to be robust for validation. 
Table 4. Fit indices for each competing model.

\begin{tabular}{lcccccccc}
\hline & $x^{2}$ & d.f. & $x^{2} /$ d.f. & NNFI & CFI & RMR & SRMR \\
\hline Null model & 5965.97 & 378 & 15.78 & - & - & - & - \\
\hline One-factor model & 3642.73 & 350 & 10.41 & 0.83 & 0.84 & 0.16 & 0.11 \\
\hline First-order-with-uncorrelated-factors model & 2365.26 & 350 & 6.76 & 0.87 & 0.88 & 0.42 & 0.31 \\
\hline First-order-with-correlated-factors model & 1703.45 & 340 & 5.01 & 0.91 & 0.91 & 0.12 & 0.079 \\
\hline Second-order hierarchy model & 1113.12 & 329 & 3.38 & 0.94 & 0.95 & 0.097 & 0.066 \\
\hline
\end{tabular}

\subsection{Cutoff-Point Criterion}

To determine an appropriate cutoff point for splitting respondents into compulsive and non-compulsive Internet buyers, the logistic regression analysis was employed. This was done to develop an optimal model of the Internet compulsive-buying tendency. A previous study [30] showed that compulsive-buying consumers have similar characteristics with those of Internet compulsive buyers. Thus, for the analysis of dichotomous dependent variables, the values of the original seven-item scale of compulsive-buying behavior proposed by Faber and O'Guinn [7] were imported into the logistic regression where traditional compulsive buyers were calculated as Internet compulsive buyers (set as 1) and general Internet buyer (set as 0 ). By using the criterion with a score of -1.34 or less (a rigorous criterion of two standard deviations from the mean, henceforth 2 SDs criterion), we conducted an empirical analysis of all the samples collected in the second round $(n=1070)$ to build up the logistic regression.

Overall, the chi-square value for the logistic regression was 885.58 , which was significant at the $p<0.001$ level. The Nagelkerke $R^{2}$ was 0.840 , which suggests a high power of explanation of independent variables on the dependent variable. The accurate prediction rate of general Internet buyers was as high as $96.9 \%$. For those subjects with the Internet compulsive-buying tendency, the hit rate was $86.9 \%$. The overall accurate-prediction rate reached $94.5 \%$, which indicated that the logistic regression could effectively improve the prediction accuracy of categorical results. The following regression formula and the scoring rules were then derived:

$\mathrm{Y}=-23.625+0.079 \times$ tendency to spend $+0.459 \times$ feelings regarding shopping and spending $+3.67 \times$ dysfunctional spending $+1.455 \times$ post-purchase guilt

Following the $2 \mathrm{SDs}$ criterion, the average value of all the constructs was 3.830 , whereas the standard deviation was 1.625. Thus, the cut value of the regression formula in this study was 7.08 , which suggests a $Y$ value $\geq 7.08$ for those Internet compulsive buyers. Conversely, if the $\mathrm{Y}$ value $<7.08$, the consumer will be classified as a normal buyer. Based on this criterion, the original individual scores in the second-round respondents were calculated through the proposed formula. The results indicated that 54 subjects from the second round of respondents can be classified as the Internet compulsive buyers because of their high tendency to shop online with a high score greater than 7.08.

\section{Conclusions, Implications, and Recommendations}

\subsection{Conclusions}

Nowadays, the telephone, mail orders, the Internet, and television retail channels have rapidly increased, all of which are competing among themselves. With this trend, due to the gradual maturity and openness of Internet technology, overall commercial forms have developed to a stage that transcends time and space. Companies not only use the Internet to develop virtual channels to establish a profit base and gain management performance but also use it to provide more online services for consumers to browse and use, such as customer-support knowledge banks, so that the public can have a choice that differs from traditional channel consumption and activity for leisure. Shopping online 
has been gradually moving towards the online sphere for a while now and has become ubiquitous due to the COVID-19 pandemic. People relied more heavily on the need to access goods without leaving their home; even more shopping and leisure sectors have moved online, making it easy and convenient to browse, use, and purchase nearly anything via the Internet. COVID-19 lockdowns have significantly changed our daily lives, with the transformation of online shopping from leisure (optional) to the "must" for living.

In the vein, a valid scale of compulsive buying enables researchers to more accurately estimate the incidence of compulsive buying, determine the trend of this behavior, and identify the affected groups [53]. Thus, a well-developed measurement scale is beneficial to test the current theory of consumer behavior. Previous studies that have investigated compulsive buying have not used an accurate scale for measuring ICBT; therefore, the main objective of this study was to develop a scale for ICBT and to use this scale to analyze the characteristics of consumers with the Internet compulsive-buying tendency.

We referred to the scales developed by related studies (e.g., Faber and O'Guinn [7]; Valence et al. [32]; Edwards [33]) and screened the items to first develop an original scale that consisted of 31 items. Following the scale-development process, we collected data with two rounds, conducted statistical analyses, and tested the data by using both EFA and CFA to determine the reliability and validity of each construct. The results indicated a high level of reliability and validity of all the indicators (internal consistency, CR, and AVE). After poor loading of items were excluded, we obtained the final scale, which consisted of 18 items. These items were grouped into four sub-constructs: the tendency to spend online, feelings about online shopping and spending, dysfunctional online spending, and online post-purchase guilt. The final research model is shown as Figure 2.

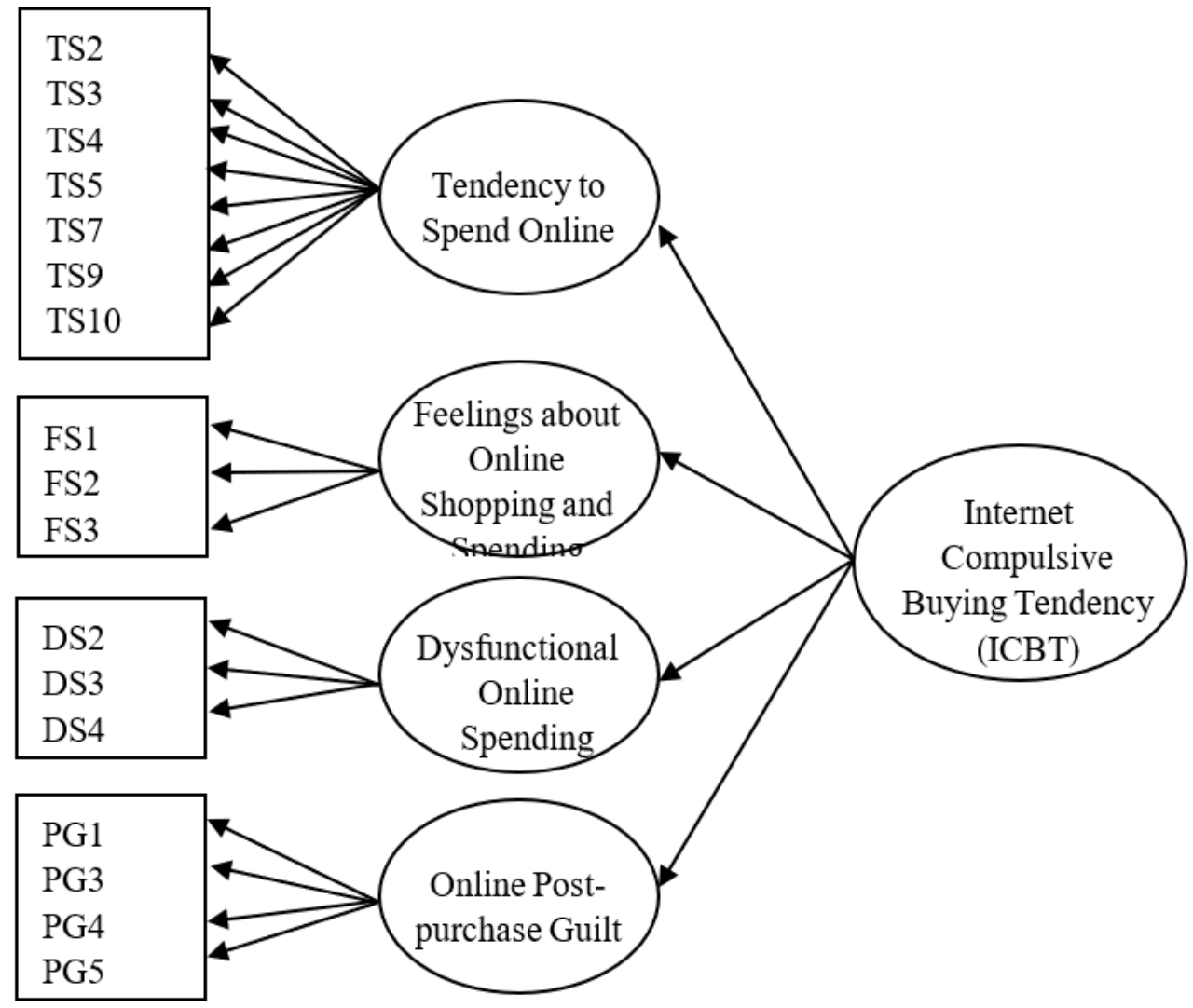

Figure 2. The refined research model.

According to the measurement items we proposed, researchers and marketers can adopt adequate marketing strategies in order to analyze the consumption patterns of individuals with the Internet buying tendency and can improve shopping services to 
increase their customer base. Individuals can also use the results of this present study to determine if they suffer from excessive consumption behavior or to avoid becoming a compulsive buyer, thus preventing financial, emotional, and interpersonal problems.

\subsection{Practical Implications}

Following the Internet's growth in importance in consumer behavior, it is critical to study its relationship with the Internet compulsive-buying tendency. Internet compulsive buying refers to an online shopping environment in which buyers pursue the temporary positive emotions associated with shopping, without planning and not using the purchased items. After a long period of time, the positive emotions obtained through excessive behavior are increasingly short-lived, which results in an increase in purchase frequency and spending. This development may adversely impact the daily lives of such buyers (e.g., their finances and social relations).

For achieving the goal of making the maximum profit, businesses should pay their efforts to target at prospective shoppers. The competition of the online shopping market is crucial, and the changes in the online market preferred by the consumer, consumer trends, and buying patterns are dynamic [54]. In addition, since the COVID-19 pandemic has also arguably accelerated technology advancement and adoption, digital transformation for businesses is the new way and issue for businesses to compete with others in the post-COVID-19 era [55]. Thus, for marketers, it is critical to understand how to target at the consumer's shopping behavior in order to understand an individual's purchase trends. In particular, during the COVID-19 pandemic, trillions of people were hunkered at home. Internet shopping became more than a way for living and possesses the characteristics that seem to encourage the compulsive-buying tendency [56-58]. Since the repetitive buying means more cardboards, delivery transportations, vehicles, and more goods being produced, it will result in unfriendly results for the environment [58]. Thus, the abnormal behavior should be identified and uncovered. Thus, a perfect predictive screening scale enables marketers to collect data on consumer behavior in order to investigate the influencing factors using statistical analysis; such an instrument enables marketers to effectively target consumers with the compulsive-buying tendency and behavior. Therefore, it is very important to have a consistent, stable measurement scale. The results of the reliability and validity tests indicated that the scale is of good quality in its fitness to the context of Internet compulsive buying. If marketers use this scale to gain insight into the preferences of consumers with the compulsive-buying tendency, the hit rate of consumers with the compulsive-buying tendency will be improved.

\subsection{Theoretical Implications}

The ICBT measurement scale developed in this study was based upon the literature to form its theoretical background. We used a quantitative method to perform an empirical test with ICBT, and the results indicated that the scale exhibited good psychometric properties in terms of reliability and validity. During the analysis stage, we conducted reliability and validity analyses and remedied the construct validity to improve the scale's measurement capability. The exclusion of poor loading items and the reduction in the scale's total number of items not only enabled the items to cover important underlying construct but also helped shorten the time required to complete the questionnaire. According to Harrell and Lee [59], for logistic regression, even if the variables were not multivariate or normal, with respect to predicting the probability, logistic regression analysis would yield more accurate results. Thus, a logistic regression was performed to derive the formula for calculating the cut value of Internet compulsive buying and key predictors.

The literature review indicated that research on this topic is not comprehensive. Thus, the results of this study can make contributions to the academic literature. This study was based on the scale for the compulsive-buying issue in traditional stores. The measurement items from key studies in this area were added and integrated to develop a scale that consisted of the following four constructs: the tendency to spend online, feelings about 
online shopping and spending, dysfunctional online spending, and online post-purchase guilt. The statistical analysis of reliability and validity of the overall scale indicated that the results for most items were significant, suggesting that the scale reached a certain level of reliability and validity and that it has a considerable level of measurement accuracy. In the future, we hope this scale can be used for additional in-depth analysis in research on Internet compulsive buying and can serve as a basis for social psychologists in their research on and observation of the characteristics of compulsive-buying symptoms. Additionally, the scale can be used to understand Internet compulsive buying and to develop methods to correct this abnormal behavior. Our literature review indicated that research on this issue is not comprehensive; therefore, we hope that the results of this study will contribute to the academic community for further investigations.

\subsection{Research Limitations and Recommendations for Future Research}

Developing a scale is an expansionary process, and adequate results must be obtained before a construct can be applied in research. This study focused on the development of a measurement scale for ICBT. Consumers should evaluate their personal-consumption patterns and changes with regard to their Internet-buying behavior over time rather than during the short period required to complete the questionnaire; therefore, we recommend that future research assess long-term observations and examinations. We also recommend that, in addition to investigating the impact of compulsive buying on compulsive buyers, future research may evaluate the causal effect of Internet compulsive buying and the impact of Internet compulsive buying on consumers' consumption outcomes.

Author Contributions: Conceptualization, H.-L.H. and Y.-Y.C.; methodology, H.-L.H.; software, Y.-Y.C.; validation, H.-L.H., Y.-Y.C. and S.-C.S.; formal analysis, H.-L.H.; investigation, Y.-Y.C.; data curation, S.-C.S.; writing-original draft preparation, H.-L.H. and Y.-Y.C.; writing-review and editing, Y.-Y.C.; visualization, S.-C.S.; supervision, H.-L.H., Y.-Y.C. and S.-C.S.; project administration, H.-L.H. All authors have read and agreed to the published version of the manuscript.

Funding: This research was funded by the Ministry of Science and Technology (MOST), Taiwan (R.O.C.) under Contract No. NSC100-2410-H-214-005-MY2.

Institutional Review Board Statement: Not applicable.

Informed Consent Statement: Not applicable.

Data Availability Statement: Not applicable.

Conflicts of Interest: The authors declare no conflict of interest.

\section{Appendix A. The Measurement Scale in the Research}

Compulsive-buying scale (source: [7]).

1. If I have any money left at the end of the pay period, I just have to spend it.

2. I felt others would be horrified if they knew my spending habits.

3. I have bought things although I could not afford them.

4. I wrote a check when I knew I did not have enough money in the bank to cover it.

5. I bought something in order to make myself feel better.

6. I felt anxious or nervous on days I do not go shopping.

7. I made only the minimum payments on my credit cards.

$($ Note: the scoring equation $=-9.69+(\mathrm{Q} 1 \times 0.33)+(\mathrm{Q} 2 \times 0.34)+(\mathrm{Q} 3 \times 0.50)+(\mathrm{Q} 4$ $\times 0.47)+(\mathrm{Q} 5 \times 0.33)+(\mathrm{Q} 6 \times 0.38)+(\mathrm{Q} 7 \times 0.31)$. If the score is $\leq-1.34$, the subject is classified as a compulsive buyer).

Tendency to spend (source: $[32,33]$ ).

TS1. When I have money, I cannot help but spend part or whole of it. (Dropped).

TS2. I am often impulsive in my online buying behavior.

TS3. When I surf the online shopping platform, I have an irresistible urge to buy something.

TS4. Sometimes I have a strong desire to shop (e.g., for clothing or CDs). 
TS5. I often have an unexplainable urge, a sudden or spontaneous desire for online shopping.

TS6. Sometimes I think there are internal forces that prompt me to shop online. (Dropped).

TS7. I often reply to direct mail offers (e.g., for books or CDs).

TS8. I often buy items that I do not need even though I know that I do not have much money left. (Dropped).

TS9. If I have money left at the end of the year, I will spend it.

TS10. Even if I do not have time and money, I still want to shop online.

TS11. I will shop online without restraint.

TS12. When I do a significant amount of online shopping, I feel a rush of high emotions. (Dropped).

TS13. Even if I do not need anything, I will still shop online. (Dropped).

TS14. When I feel frustrated, angry, or disappointed, I will shop online without restraint. (Dropped).

TS15. I buy things that I do not need or will not use. (Dropped).

TS16. Sometimes I must shop online. (Dropped).

Feelings regarding shopping and spending (source: [32,33]).

FS1. For me, online shopping is a way to reduce life pressure each day.

FS2. I feel good about myself through online shopping.

FS3. I get little or no fun during online shopping.*

FS4. I hate online shopping.* (Dropped).

* Reverse item

Dysfunctional online spending (source: [32,33]).

DS1. When I know I do not have enough money, I borrow money to pay for online shopping. (Dropped).

DS2. I only pay the minimum balance on my credit card.

DS3. I am worried about my spending habits, but I still shop online as usual.

DS4. Even if I cannot afford it, I still want to shop online.

Online post-purchase guilt (source: [32,33]).

PG1. Sometimes I feel that my online shopping behavior seems to be irrational.

PG2. I think if others knew about my spending habits, I would be afraid. (Dropped).

PG3. Because I am afraid that others will think my online-shopping behavior is irrational, I do not want to show certain items to others.

PG4. No online shopping makes me feel that life is full of stress and anxiety.

PG5. I feel anxiety after unrestrained online shopping.

PG6. I feel guilt or shame after unrestrained online shopping. (Dropped).

PG7. I sometimes think that I might feel sorry for my behavior if I constantly shop online. (Dropped).

\section{References}

1. Chen, L.D.; Gillenson, M.L.; Sherrell, D.L. Enticing online consumers: An extended technology acceptance perspective. Inf. Manag. 2002, 39, 705-719. [CrossRef]

2. Liu, Q.; Zhang, X.; Huang, S.; Zhang, L.; Zhao, Y. Exploring consumers' buying behavior in a large online promotion activity: The role of psychological distance and involvement. J. Theor. Appl. Electron. Commer. Res. 2020, 15, 66-80. [CrossRef]

3. Vicdan, H.; Sun, J. Towards a framework for understanding compulsive buyers online: Exploring the effects of online sales promotions. In Proceedings of the 39th Southwest Decision Sciences Institute Annual Conference, Houston, TX, USA, 6-8 March 2008; pp. 598-607.

4. Bressolles, G.; Durieu, F.; Giraud, M. The impact of electronic quality's dimensions on customer satisfaction and buying impulse. J. Consum. Behav. 2007, 6, 37-56. [CrossRef]

5. Rook, D.W.; Fisher, R.J. Normative influences on impulsive buying behavior. J. Consum. Res. 1995, 22, 305-313. [CrossRef]

6. McElroy, S.L.; Paul, E.K.; Harrison, G.P.; Mark, J.S.; Stephen, M.S. Compulsive buying: A report of 20 cases. J. Clin. Psychiatry 1994, 55, 242-248. [PubMed]

7. Faber, R.J.; O'Guinn, T.C. A clinical screener for compulsive buying. J. Consum. Res. 1992, 19, 459-469. [CrossRef]

8. Krych, R. Abnormal consumer behaviour: A model of addictive behaviours. Adv. Consum. Res. 1989, 16, 745-748. 
9. Hassay, D.N.; Smith, M.C. Compulsive buying: An examination of the consumption motive. J. Psychol. Mark. 1996, 13, 741-752. [CrossRef]

10. Lee, Y.L.; Park, J.K. The mediating role of consumer conformity in e-compulsive buying. Adv. Consum. Res. 2008, 35, 387-392.

11. Kukar-Kinney, M.; Ridgway, N.M.; Monroe, K.B. The relationship between consumers' tendencies to buy compulsively and their motivations to shop and buy on the Internet. J. Retail. 2009, 85, 298-307. [CrossRef]

12. LaRose, R.; Eastin, M.S. Is online buying out of control? Electronic commerce and consumer self-regulation. J. Broadcast. Electron. Media 2002, 46, 549-564. [CrossRef]

13. Black, D.W.; Gabel, J.; Hansen, J.; Schlosser, S. A double-blind comparison of fluvoxamine versus placebo in the treatment of compulsive buying disorder. Ann. Clin. Psychiatry 2000, 12, 205-211. [CrossRef] [PubMed]

14. Greenfield, D.N. Virtual Addition; New Harbinger: Oakland, CA, USA, 1999.

15. d'Astous, A.; Maltais, J.; Roberge, C. Compulsive buying tendencies of adolescent consumers. Adv. Consum. Res. 1990, 17, 306-312.

16. Faber, R.J. Money changes everything: Compulsive buying from biopsychosocial perspective. Am. Behav. Sci. 1992, 35, 809-819. [CrossRef]

17. O'Guinn, T.C.; Faber, R.J. Compulsive buying: A phenomenological exploration. J. Consum. Res. 1989, 16, 147-157. [CrossRef]

18. Solomon, R.C. In Defense of Sentimentality; Oxford University Press: New York, NY, USA, 2004.

19. Kraepelin, E. Psychiatrie, 8th ed.; Verlag Von Johann Ambrosurs Barth: Leipzig, Germany, 1927; Volume 4, pp. $408-409$.

20. Bleuler, E. Textbook of Psychiatry; Macmillan: New York, NY, USA, 1924.

21. Faber, R.J.; O'Guinn, T.C.; Krych, R. Compulsive consumption. Adv. Consum. Res. 1987, 14, 132-135.

22. Lejoyeux, M.; Weinstein, A. Compulsive buying. Am. J. Drug Alcohol Abuse 2010, 36, 248-253. [CrossRef] [PubMed]

23. Ninan, P.T.N.; McElroy, S.; Kane, C.P.; Knight, B.T.; Casuto, L.S.; Rose, S.E. Placebo-controlled study of fluvoxamine in the treatment of patients with compulsive buying. J. Clin. Psychopharmacol. 2000, 20, 362-366. [CrossRef] [PubMed]

24. Elliott, R. Addictive consumption: Function and fragmentation in postmodernity. J. Consum. Policy 1994, 17, 159-179. [CrossRef]

25. Alba, J.; Lynch, J.; Weitz, B.; Janiszewski, C.; Sawyuer, A.; Wood, S. Interactive home shopping: Consumer, retailer, and manufacturer incentives to participate in electronic marketplaces. J. Mark. 1997, 61, 38-53. [CrossRef]

26. Grewal, D.; Iyer, G.R.; Levy, M. Internet retailing: Enablers, limiters and market consequences. J. Bus. Res. 2004, 57, 703-711. [CrossRef]

27. O'Cass, A.; Fenech, T. Web retailing adoption: Exploring the nature of Internet users web retailing behaviour. J. Retail. Consum. Serv. 2003, 10, 81-94. [CrossRef]

28. Lee, S.H.; Lennon, S.L.; Rudd, N.A. Compulsive consumption tendencies among television shoppers. Fam. Consum. Sci. Res. J. 2000, 28, 463-489. [CrossRef]

29. LaRose, R. On the negative effects of e-commerce: A sociocognitive exploration of unregulated on-line buying. J. Comput. Mediat. Commun. 2001, 6, JCMC631. Available online: http:/ / www.ascuse.org/jcmc/vol6/issue3/larose.html (accessed on 12 June 2015). [CrossRef]

30. Ridgway, N.M.; Kukar-Kinney, M.; Monroe, K.B. An expanded conceptualization and a new measure of compulsive buying. J. Consum. Res. 2008, 35, 622-639. [CrossRef]

31. Faber, R.J.; O'Guinn, T.C. Compulsive consumption and credit abuse. J. Consum. Policy 1988, 11, 97-109. [CrossRef]

32. Valence, G.; d'Astous, A.; Fortier, L. Compulsive buying: Concept and measurement. J. Consum. Policy 1988, 11, 419-433. [CrossRef]

33. Edwards, E.A. Development of a new scale for measuring compulsive buying behavior. Financ. Couns. Plan. 1993, 4, 67-84.

34. Churchill, G.A. A paradigm for developing better measures of marketing constructs. J. Mark. Res. 1979, 16, 64-73. [CrossRef]

35. Hinkin, T.R. A review of scale development practices in the study of organizations. J. Manag. 1995, 21, 967-988. [CrossRef]

36. Ridgway, N.M.; Kukar-Kinney, M.; Monroe, K.B. The Measurement of Compulsive Buying and Its Application to Internet Buyers. In Compulsive Buying: Clinical Foundations and Treatment; Müller, A., Mitchell, J., Eds.; Taylor Francis: New York, NY, USA, 2011; pp. 51-62.

37. Wang, C.C.; Yang, H.W. Passion and dependency in online shopping activities. CyberPsychol. Behav. 2007, 10, 296-298. [CrossRef]

38. Kerlinger, F.; Lee, H. Foundations of Behavioral Research; Thomson Learning: Stamford, CT, USA, 2000.

39. Nunnally, J.C. Psychometric Theory, 2nd ed.; Mc-Graw-Hill: New York, NY, USA, 1978.

40. Kaiser, H.F. An index of factorial simplicity. Psychometrika 1974, 19, 31-36. [CrossRef]

41. Hair, J.F.; Black, W.C.; Babin, B.J.; Anderson, R.E.; Tatham, R.L. Multivariate Data Analysis; Pearson Education Inc.: Upper Saddle River, NJ, USA, 2006.

42. Bentler, P.M.; Chou, C.P. Practical issues in structural modeling. Sociol. Methods Res. 1987, 16, 78-117. [CrossRef]

43. Bollen, K.A. Structural Equations with Latent Variables; John Wiley: New York, NY, USA, 1989.

44. Bagozzi, R.P.; Yi, Y. On the evaluation of structural equation model. J. Acad. Mark. Sci. 1988, 16, 74-94. [CrossRef]

45. Fornell, C.; Larcker, D.E. Evaluating structural equation models with unobservable and measurement error. J. Mark. Res. 1981, 18, 39-50. [CrossRef]

46. Jöreskog, K.G.; Sörbom, D. LISREL 7: A Guide to the Program and Applications; SPSS: Chicago, IL, USA, 1989 ; Volume 2.

47. Bagozzi, R.P. An examination of the validity of two models of attitude. Multivar. Behav. Res. 1981, 16, 323-359. [CrossRef]

48. Wang, Y.S. Development and validation of a mobile computer anxiety scale. Br. J. Educ. Technol. 2007, 38, 990-1009. [CrossRef] 
49. Hinkin, T.R. A brief tutorial on the development of measures for use in survey questionnaires. Organ. Res. Methods 1988, 1, 104-121. [CrossRef]

50. Ajzen, I. The theory of planned behavior. Organ. Behav. Hum. Decis. Processes 1991, 50, 179-211. [CrossRef]

51. Vasquez, F.; Vera-Martinez, J. From e-quality and brand perceptions to repurchase: A model to explain purchase behaviours in a web-store. J. Theor. Appl. Electron. Commer. Res. 2020, 15, 20-36. [CrossRef]

52. Noar, S.M. The role of structural equation modeling in scale development. Struct. Equ. Modeling 2003, 10, 622-647. [CrossRef]

53. Manolis, C.; Roberts, J.A. Compulsive buying: Does it matter how it's measured? J. Econ. Psychol. 2008, 29, 555-576. [CrossRef]

54. Suki, N.M. Consumer shopping behaviour on the Internet: Insights from Malaysia. Electron. Commer. Res. 2013, 13, 477-491. [CrossRef]

55. Lim, W.M. Editorial: History, lessons, and ways forward from the COVID-19 pandemic. Int. J. Qual. Innov. 2021, 5, 101-108.

56. Koch, J.; Frommeyer, B.; Schewe, G. Online shopping motives during the COVID-19 pandemic- Lessons from the crisis. Sustainability 2020, 12, 10247. [CrossRef]

57. Muangmee, C.; Kot, S.; Meekaewkunchorn, N.; Kassakorn, N.; Khalid, B. Factors determining the behavioral intention of using food delivery apps during COVID-19 pandemics. J. Theor. Appl. Electron. Commer. Res. 2021, 16, 1297-1310. [CrossRef]

58. Alaimo, L.S.; Fiore, M.; Galati, A. How the COVID-19 Pandemic Is Changing Online Food Shopping Human Behaviour in Italy. Sustainability 2020, 12, 9594. [CrossRef]

59. Harrel, F.E.; Lee, K.L. A comparison of the discrimination of discriminant analysis and logistic regression under multivariate normality. In Biostatistics: Statistics in Biomedical, Public Health and Environmental Sciences; Sen, P.K., Ed.; Elsevier Science Publisher: North-Holland, The Netherlands, 1985; pp. 333-343. 